\title{
A Successful Management of 29 year old Female with Left Central Retinal Artery Occlusion due to Manifestation of Primary Antiphospholipid Syndrome
}

\author{
Herman Bagus Trianto', Cesarius Singgih Wahono', Nadia Artha Dewi
}

\begin{abstract}
1 Division of
Rheumatology and Immunology, Internal Medicine Department, Brawijaya UniversitySaiful Anwar General Hospital Malang ${ }^{2}$ Division of Vitreoretina, Ophthalmology Department, Brawijaya University- Saiful Anwar General Hospital Malang
\end{abstract}

Department of Internal Medicine. Faculty of Medicine, Brawijaya University - dr. Saiful Anwar General Hospital. Jl. Jaksa Agung Suprapto no.2, Malang 61351, Indonesia. Correspondence mail: drhermanbagustrianto@ yahoo.com.

\begin{abstract}
Ocular involvement in Anti Phospolipid Syndrome (APS) includes a broad spectrum of manifestations from the anterior and posterior segment or the presence of neuro-ophthalmologic features. A female, 29 years old, came to ER handled by ophthalmology department, with chief complaint left visual loss suddenly since 4 hours before admission. Investigations revealed stable vital signs, VOD 20/20, VOS 1/300, funduscopy showed pale and cherry red spot on left retina, OCT revealed hyperreflective of left inner retinal layer, IgG aCL $51.7 \mathrm{U} /$ $\mathrm{mL}(50.8 \mathrm{U} / \mathrm{mL}$ in OPD 3 months later), and the other examinations were within normal limit. Patient was diagnosed with Central Retinal Artery Occlusion due to Primary Antiphospolipid syndrome. She was performed occular massage and anterior chamber paracintesis procedure, and given 02 6-8 Ipm NRBM, Timolol 0.5\% eye drop left eye bid, acetazolamide $250 \mathrm{mg}$ bid, Kalium Slow Release 1 tab qd, Levofloxacine eye drop 1 drop/ hour post surgery. After the result of IgM aCL available, we added warfarin $2 \mathrm{mg}$ qd and aspirin $320 \mathrm{mg}$ qd. Patient was discharged 2 days later as visual acuity improved with VOD 20/20 and VOS 0.5/60.
\end{abstract}

\section{Key words:}

Central retina artery occlusion, primary anti phospolipid syndrome, anti cardiolipin antibody

\section{Introduction}

Ocular involvement in APS includes a broad spectrum of manifestations from the anterior and posterior segment or the presence of neuroophthalmologic features. ${ }^{1-4}$ In brief, conjuctival telangiectasia or conjuctival microaneurysms, episcleritis, limbal or filamentary keratitis and iritis have been described as the APS ocular features from the anterior segment, ${ }^{5-9}$ vitritis, retinal detachment, posterior scleritis, branch or central retinal vein occlusion, bilateral choroidal infarction, cilioretinal artery occlusion, venous tortuosity, retinal hemorrhages, cotton-wool spots and central serous type chorioretinopathy from the posterior segment ${ }^{4,8}$ and monocular or bilateral transient visual loss, transient visual field loss, ischemic optic neuropathy and progressive optic nerve atrophy as the neuroophthalmologic features of APS. It is estimated that the incidence opf APS is approximately 5 cases per 100.000 persons per year, and $88 \%$ of primary APS involved ocular involvements. ${ }^{4,5}$

However, case report of the ocular manifestations as the prevailing sign of APS in patients suffering from "unexplained" ocular disease are seldom. Herein, we report a sudden left eye visual loss in a young female without any other risk factors of thrombosis as first manifestation of APS in Malang, Indonesia.

\section{Case Illustration}

A female, 29 years old, came to ER handled by ophthalmology department, with chief complaint left visual loss suddenly since 4 hours before admission when she was playing with her nephews on the bed. Her left eye suddenly could not see anything after she got up from lying on bed. It was painless, persistent, non progressive, and redless. There were no history of joint pain, skin rash, hair loss, fever, eye disease, and episodes of thrombosis before. There weren't also history of trauma, hypertension, diabetes, dyslipidemia, malignancy, heart disease, blood disorders, nor other systemic diseases. However, both parents passed away due to heart disease and stroke as complications of DM and hypertension. She is an accountant, not yet married, and had regular period. She had never consumed routine medications and had no drug allergy.

Physical examination revealed blood pressure $110 / 70 \mathrm{mmHg}$, pulse rate $84 \mathrm{bpm}$, respiratory rate $12 \mathrm{tpm}$, axillary temperature $36.7 \mathrm{C}$, body weight $56 \mathrm{~kg}$, body height $158 \mathrm{~cm}$, and BMI $22.4 \mathrm{~kg} / \mathrm{m}^{2}$, VOD 20/20, VOS 1/300, intra occular pressure OD was $19.6 \mathrm{mmHg}$ whether OS was $23 \mathrm{mmHg}$. Funduscopy showed pale and cherry red spot on left retina. Optical Coherence Tomography (OCT) of the left eye revealed hyperreflective of inner retinal layer that was a sign of intraretinal oedema and ischemia. Anterior segment and the other examinations were within normal limit. 
Figure 1. Retina Photo of the Patients Showing CRAO (Cherry Red Spot and Pale of the Retina)
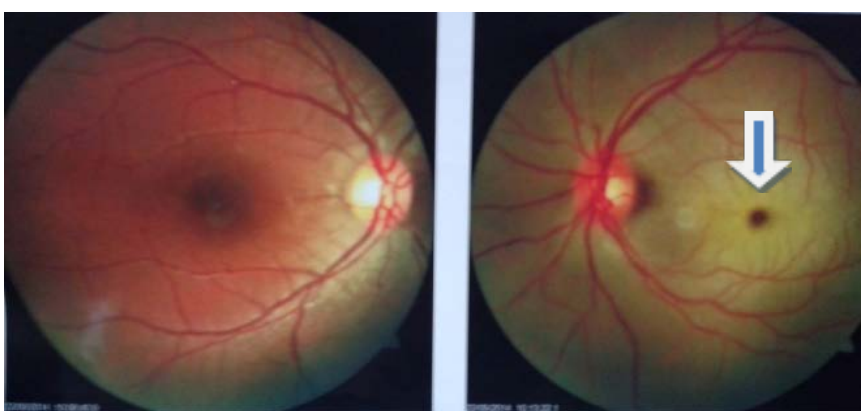

Laboratory result showed hemoglobin level $13.60 \mathrm{~g} / \mathrm{dl}$, leukocyte count $7.240 / \mu \mathrm{L}$, hematocrite $40.60 \%$, thrombocyte count $281.000 / \mu \mathrm{L}$, (diff count 0.4/0.3/68.6/27.2/3.5). PPT was 11.10 second, aPTT was 29.80 (within normal limit), INR 0.96, random blood glucose $83 \mathrm{mg} / \mathrm{dL}$, Ureum $17.70 \mathrm{mg} / \mathrm{dL}$, Creatinine $0.60 \mathrm{mg} / \mathrm{dL}$, CRP $0.10 \mathrm{mg} / \mathrm{dL}$, ESR $19 \mathrm{~mm} / \mathrm{hour}$, fasting blood glucose $72 \mathrm{mg} / \mathrm{dL}, 2$ hours post prandial glucose $92 \mathrm{mg} / \mathrm{dL}$, Hba1c 4.60\% (average blood glucose $85.3 \mathrm{mg} / \mathrm{dL}$ ), total cholesterol $175 \mathrm{mg} / \mathrm{dL}$, triglyceride $56 \mathrm{mg} / \mathrm{dL}$, HDLc 41 $\mathrm{mg} / \mathrm{dL}$, and LDLc $92 \mathrm{mg} / \mathrm{dL}$, antidsDNA 66.2 IU/mL $(\mathrm{N}<$ 92.6), and ANA test (ELISA) $0.1(\mathrm{~N}<1)$ units. ECG showed sinus rhytm heart rate $80 \mathrm{x} / \mathrm{m}$.

Patient was consulted to internal medicine department to investigate possible cause of blood vessel occlusion in this patient. We suggest to checked for aCL for screening of APS. The result showed IgG anti cardiolipin antibody $51.7 \mathrm{U} / \mathrm{mL}$. We checked again 3 months later in Outpatient Department showed $50.8 \mathrm{U} / \mathrm{mL}$.

Figure 2. OCT of Left Eye (Right Picture) that Revealed Hyperreflective of Inner Retinal Layer, Compared to Right Eye (Left Picture) that Was Within Normal Limit

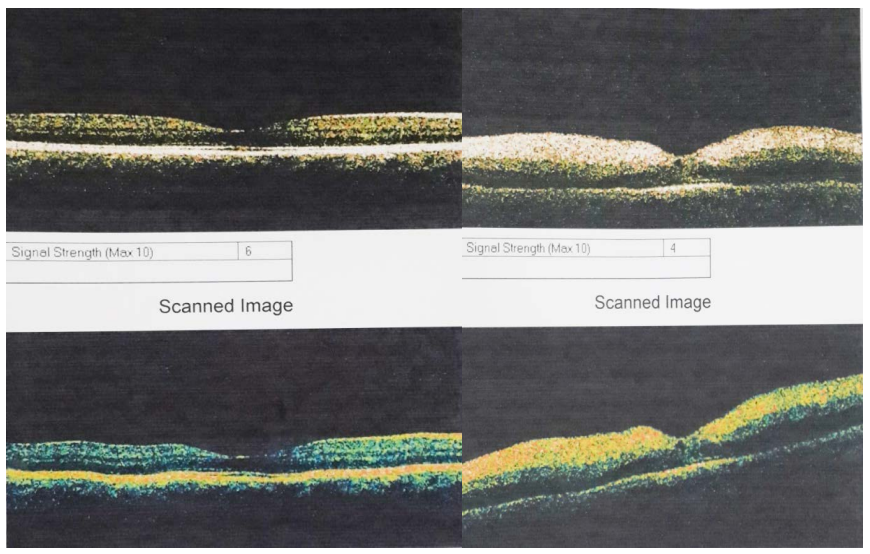

Patient was diagnosed as Central Retinal Artery Occlusion due to Primary Antiphospolipid syndrome. She was performed occular massage and anterior chamber parasintesis procedure, and given $\mathrm{O} 2$ 6-8 lpm NRBM, Timolol $0.5 \%$ eye drop bid on the left eye, acetazolamide $250 \mathrm{mg}$ bid, Kalium Slow Release 600mg qd, and Levofloxacine eye drop 1 drop/hour post surgery. After the result of IgG aCL available, we added warfarin $2 \mathrm{mg}$ qd and aspirin $320 \mathrm{mg}$ qd. Patient was discharged 2 days later with improvement of visual acuity (VOD 20/20 and VOS 0.5/60), and aspirin was stopped afterward in OPD with uptitrating warfarin as INR target reached 3.0.

\section{Discussion}

Antiphospolipid syndrome is a hypercoagulable disorder manifested by recurrent arterial and venous thromboses and adverse outcomes in pregnancy that is associated with antiphospolipid (aPL) antibodies. ${ }^{6}$ The pathophysiology of retinal artery occlusion in APS is poorly understood, although aPL is implicated in this disorder. aPL affects coagulation and thrombosis in different ways: (1) these antibodies may bind to platelets, upregulating production of thromboxane A2 and expression of glycoprotein $2 \mathrm{~b}-3 \mathrm{a}$, to endothelial cells and monocytes which increase production of tissue factors; or to endothelial cells resulting in an increase in adhesion molecules; which all of them interacts causing thrombosis, (2) the binding of aPL also activates complement, which can initiate an inflammatory cascade resulting in thrombosis. Complement activation has also been linked to fetal loss in APS, (3) another journals also mentioned that coagulation may result from disruption of proteins that regulate thrombosis, such as protein $\mathrm{C}$, by aPL, also antibodies against $\beta-2$ glycoprotein I ( $\beta$-2gpI), a naturally occuring anticoagulant, may induce a prothrombotic state, (4) cardiovascular risk factors such as smoking and estrogen use can help promote thrombosis in APS.

This case demonstrated that the ocular features as the first presenting sign of APS though rare, should alert the clinicians for APS possibility, particularly when conventional risk factors have been excluded and the onset of ocular symptoms are insidious. ${ }^{5,7,9,11-16}$ Although the involvement of anterior segment is not rare, the manifestations from the posterior segment such as vasculitis, vitritis, retinal detachment, posterior scleritis and central retinal artery occlusion appear to be more prominent among APS patients. ${ }^{4,8}$ Of these, the most common and the most serious is vasculitis, which can result in vasoocclusive disseminated retinopathy. In our case, the patient came with central retinal artery occlusion without any involvement of anterior segment and neuroophthalmology.

Acutely, obstruction of the central retinal artery results in inner layer edema and pyknosis of the ganglion cell nuclei. Ischemic necrosis results, and the retina becomes opacified and yellow-white in appearance. The opacity is most dense in the posterior pole as a result of the increased thickness of the nerve fiber layer and ganglion cells in this region. Furthermore, the foveola assumes a cherry-red spot because of a combination of 2 factors: (1) the intact retinal pigment epithelium and choroid underlying the fovea, and (2) the foveolar retina is nourished by the choriocapillaris. The late stage shows a homogenous scar replacing the inner layer of the retina. ${ }^{4,6}$

The updated International Consensus Statement on classification criteria for definite APS states that the diagnosis of APS should be considered when at least one Clinical Criteria ( (1) Vascular thrombosis, or (2) Pregnancy morbidity; (a) one or more unexplained deaths of a morphologically normal fetus 
at or beyond the $10^{\text {th }}$ week, $(\mathrm{b})$ one or more pre-term births of a morphologically normal neonate before the $34^{\text {th }}$ week of gestation because of eclampsia, severe pre-eclampsia, or recognized features of placental insufficiency, (c) three or more consecutive spontaneous miscarriage before the $10^{\text {th }}$ week of gestation with maternal anatomic, hormonal abnormalities, and chromosomal causes excluded) and one Laboratory Criteria ( (1) Lupus anticoagulant (LA), (2) Anticardiolipin $(\mathrm{aCL})$ antibody of $\operatorname{IgG}$ and/or IgM isotype, or (3) Anti- $\beta 2$ glycoprotein I antibody of IgG and/or IgM isotype, all of those three present in plasma or serum on two or more occasions at least 12 weeks apart). ${ }^{7,10}$ Patient in our case presented with arterial thrombosis at central retinal artery and elevated titer IgM aCL on 2 separated examinations, thus already fulfilled diagnostic criteria.

Prevention of thrombosis is a major goal of therapy in patients with aPL antibodies. Therapy is divided into 2 clinical settings: primary prophylaxis (aPL carriers without previous thrombosis) and secondary prophylaxis (patient with APS who have already had a thrombotic events). ${ }^{7-8}$

For patients with documented thrombotic events, long term intensive anticoagulation is recommended on the basis for the type of thrombotic events. Venous events can be treated with unfractionated IV heparin followed by warfarin with a goal INR of 2.5 (range 2-3). Recurrent venous thrombosis has been reported from 3\%-24\% per year and if it happened, high intensity anticoagulant is recommended (INR range 3-4), or warfarin (INR 2-3) plus aspirin, or switching to LMWH if unstable INR. Evidence to treat arterial event is still lack of evidence. Current therapy includes aspirin only ( $325 \mathrm{mg} /$ day) and / or warfarin therapy at moderate / high dose. ${ }^{7,9}$

The mainstay of therapy for CRAO is procedure and pharmacologic therapy. Occular massage can dislodge the embolus to a point further down the arterial circulation and improve retinal perfusion. Anterior chamber parasentesis can be performed as a decrease in intraocular pressure is believed to allow greater perfusion, pushing emboli further down the vascular tree. Intra-arterial fibrinolysis is controversial. Limited evidence of improved visual acuity with urokinase is available. A few cases of intra-arterial tissue plasminogen activator (tPA) administration have been observed to be successful. ${ }^{18}$

Immediate medical care to lower IOP includes acetazolamide $500 \mathrm{mg}$ IV/PO once daily and other topical medications. Carbogen therapy $(5 \% \mathrm{CO} 2,95 \%$ O2) may dilates retinal arterioles and increase oxygen delivery to ischaemic tissue. Hyperbaric oxygen therapy may beneficial if begun within 2-12 hours of onset ${ }^{18}$

Our patient was treated by both rheumatology and ophthalmology department. We gave high dose aspirin and warfarin with target INR 3.0 at the beginning as secondary prophylaxis to prevent another episodes of thrombosis and worsening of arterial occlusion. Ophthalmology department underwent prompt oxygen administration, occular massage, anterior chamber parasentesis, and pharmacological treatment to lower intra occular pressure (acetazolamide, timolol) for giving greater perfusion in the left eye as visual acuity improved. Other therapy modality were not available or still debatable about the benefit.

APS prognosis clearly depends on the severity of the disease, the thrombotic events, recurrences and the side effects of treatment. ${ }^{3}$ However, the prognosis of ocular diseases due to APS is not well documented, as long-lasting prospective studies are missing. Though there is still no definite agreement for the duration of anticoagulant treatment, it seems rational and prudent to treat these patients lifelong targeting an INR between $>3.0$, while the role, if any, of corticosteroids is unclear. ${ }^{7,9,17}$

\section{Conclusion}

Antiphospolipid syndrome must be suspected in every patient with retinal artery occlusion without any other risk factors. Early diagnosis and prompt treatment are very important to improve visual acuity and prognosis. Collaboration between ophthalmology and rheumatology divisions is needed to support proper management for such particular patients.

\section{References}

1. Miyakis S, Lockshin MD, Atsumi T, Branch DW, Brey RL, Cervera R, et al. International consensus statement on an update of the classification criteria for definite antiphospholipid syndrome (APS). J Thromb Haemostasis. 2006; 4(2):295-306.

2. Dalekos GN, Zachou K, Liaskos C. The antiphospholipid syndrome and infection. Curr Rheumatol Rep. 2001; 3: 277-285.

3. Khamashta MA, Bertolaccini ML, Hughes GR. Antiphospholipid (Hughes) syndrome. Autoimmunity. 2004; 37:309-312.

4. Cabrita FVL, Foster CS. Anticardiolipin antibodies and ocular disease. Ocul Immunol Inflamm. 2005; 13:265-270.

5. Giorgio D, Gabrieli CB, Bonomo L. The clinico-ophthalmological spectrum of antiphospholipid syndrome. Ocul Immunol Inflamm. 1998; 6:269-273.

6. Kalogeropoulos CD, Spyrou P, Stefaniotou MI, Tsironi EE, Drosos AA, Psilas KG. Anticardiolipine antibodies and occlusive vascular disease of the eye: a prospective study. Doc Ophthalmol. 1998; 2:109-112.

7. Davila L, Joseph A, editor. Rheumatology subspeciality consult: anti phospolipid syndrome. $2^{\text {nd }}$ Edition. Phyladelphia: Lippincott Williams \& Wilkins: 2012, 39:329-335.

8. Rand JH. Molecular pathogenesis of the antiphospolipid syndrome. Circ Res. 2002; 90:29-37.

9. Lim W, Crowther MA, Eikelboom JW. Management of antiphospholipid antibody syndrome: a systematic review. JAMA. 2006; 295 (9): 1050 1057.

10. Keeling D, Mackie I, Moore GW, Greer IA, Greaves M. Guidelines on the investigation and management of antiphospolipid syndrome. British Journal of Hematology. 2012; 157: 47-58.

11. Cobo-Soriano R, Sanchez-Ramon S, Aparicio MJ, Teijeiro MA, Vidal P, Suárez-Leoz M, et al. Andiphospholipid antibodies and retinal thrombosis in patients without risk factors: a prospective case-control study. Am J Ophthalmol. 1999; 6:725-732

12. Miserocchi E, Baltatzis S, Foster CS: Ocular features associated with anticardiolipin antibodies. Am J Ophthalmol. 2001:131:451-456.

13. Bolling JP, Brown GC: The antiphospholipid antibody syndrome. Curr Opin Ophthalmol. 2000;11:211-213.

14. Tsironi E, Gatselis N, Kotoula MG, Chatzoulis DZ, Dalekos GN: Unxplained choroidal embolization: remember the antiphospholipid syndrome. Lancet. 2006; 368:1936. 
15. Marcucci R, Sodi A, Giambene B, Liotta AA, Poli D, Mannini L, Falciani M, Abbate R, Menchini U, Prisco D: Cardiovascular and thrombophilic risk factors in patients with retinal artery occlusion. Blood Coag Fibrin. 2007; 18:321-326.

16. Cahill M, Stinnett SS, Fekrat S: Meta-analysis of plasma homocysteine, serum folate, serum vitamin B12 and thermolabile MTHFR genotype as risk factors for retinal vascular occlusive disease. Am J Ophthalmol. 2003; 136:1136-1150.
17. Miyakis S. International consensus statement on an update of the classification criteria for definite antiphospholipid syndrome (APS). J Thromb haemost. 2006; 4:295-306.

18. Graham RH. Central Retinal Artery Occlusion. Opthlmology. 1980 Jan; 87 (1):75-78 
